\title{
Truffaldino, Pantalone, Riciulina. As commedie di maschere e a música no período barroco em Roma e outras cidades
}

\author{
Teresa Chirico \\ (Conservatorio di musica "L. Refice" di Fosinone) \\ Tradução: Silvana Scarinci e Denise Scandarolli
}

(UFPR/UNICAMP)

Resumo: Crônicas e documentos do período barroco em Roma - entre século XVII e XVIII - trazem relatos sobre "comediantes" e saltimbancos. Naquela época, o teatro de máscaras era considerado um gênero menos nobre se comparado aos melodramas e oratórios. Permanecem muitas dúvidas sobre estas obras, mas nova documentação vem iluminar a atividade destes comediantes em teatros e palácios da aristocracia romana. Deste modo, podemos apreciar e compreender a importância destas peças em Roma e outras cidades italianas. Uma questão ainda sem respostas diz respeito à música utilizada nestas obras: meu estudo busca investigar o assunto através de documentos históricos, fontes iconográficas, relatos sobre instrumentos musicais.

Palavras-chave: Commedie no Barroco; Teatro e música barroca; Roma e comédias; Família Ottoboni e comédias.

TRUFFALDINO, PANTALEONE, RICULINA. COMMEDIE DI MASCHERA AND BAROQUE MUSIC IN ROME AND OTHER CITIES

Abstract: Chronicles and documents dated back to the Roman Baroque period between XVII and XVIII centuries - tell us about performances of "comedians" and "mountebanks". At the time, mask play was considered a less noble genre if compared to melodramas and oratorios. There are still many doubts about those plays, but new statements now shine a light on the activity of those comedians in theatres and palaces of the Roman aristocracy. In this way, we can appreciate and understand the importance and consideration of those plays in Rome and in other Italian cities. A matter still unresolved is represented by music in those plays: my study wants to investigate the issue by documentary testimonies, iconographical sources, news about musical instruments.

Keywords: Comedies and Baroque; Theatre and Baroque Music; Rome and Comedies; The Ottoboni family and comedies.

'Commedia delle maschere, commedia dell'arte e commedie degli istrioni são nomes distintos para a mesma manifestação teatral/musical, sendo utilizada em suas diversas formas em lugares diversos. 
Durante os séculos XVI e XVII, os textos das commedie di maschere não eram publicados como ocorria com outros gêneros considerados mais "nobres", por exemplo os melodramas, com música do começo ao fim, os quais frequentemente chegavam à versão impressa. Muitas das obras de commedia se baseavam em canovacci, ou seja, enredos descritos resumidamente, sobre os quais os atores improvisavam. Considera-se que a ausência de documentos impressos causou a perda deste gênero de teatro no decorrer do tempo.

Os textos editados de commedia que ainda sobrevivem revelam, às vezes, a existência de música no Prólogo, nos intermezzi entre os atos, nos balli. Certamente, algumas partes do corpo da comédia também eram cantadas (mesmo que não encontremos indicações explícitas sobre isto) e de maneira particular nos trechos que se apresentam em forma de versos entre as partes em prosa. Além disto, os atores introduziam peças musicais ad libitum. A pesquisa sobre esta música, baseada nos textos editados e ainda remanescentes traz frutos quase inexistentes. No entanto, não podemos mais excluir a hipótese de que algumas dessas músicas tenham sobrevivido, talvez em forma manuscrita sem apresentar nenhum indício em relação ao contexto teatral no qual se inseriam.

Crônicas e documentos narram as performances musicais de comici e saltimbanchi, mas frequentemente não informam detalhes sobre a música executada. Estamos longe ainda de saber quantas e quais tipos de músicas se faziam presentes nas commedie di maschere. O meu estudo, que se baseia no exame de fontes textuais, documentos inéditos, notícias sobre instrumentos musicais, fontes iconográficas, tende a traçar algumas diretrizes sobre as maschere e a música, particularmente em Roma. Este tema se entrelaça inevitável e inseparavelmente com a história da presença deste gênero musical em outros territórios, justamente pela natureza 'nômade' das companhias, que levavam sua arte em turnês pela península italiana e além dos Alpes. 


\section{Música sobrevivente e instrumentos musicais nas commedie di maschere.}

Encontramos ainda hoje a música de algumas danças nas commedie di maschere italianas, as sfessanie, imortalizadas nas gravuras I balli di Sfessanìa (1621-22), de Jacques Callot di Nancy, que esteve em Roma, em 1608 e, entre 1612 e 1621, em Florença, sob a proteção de Cristina di Lorena. Callot fez suas gravuras em 1621, quando retornou a Nancy após a estadia na Itália. Não sabemos em qual cidade italiana ele assistiu tais commedie. La sfessanìa era un ballo em voga em Nápoles, no século XVI, e podia ser cantado². Diversos instrumentos musicais (sobretudo napolitanos) são representados na obra de Callot, como o colascioni, ${ }^{3}$ guitarras, pandeiros, guizos.

Fig. 1 - Balli di Sfessanìa, British Museum, X,4.460

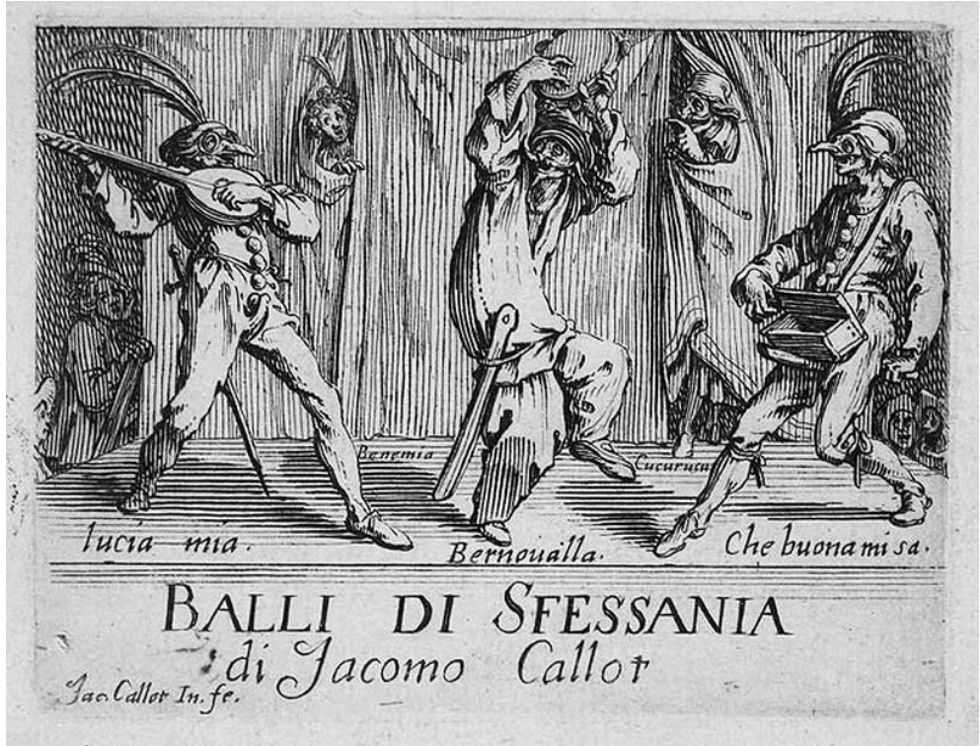

${ }^{2}$ Giovanni Battista del Tufo, Ritratto o modello delle grandezze, delitie e maraviglie della Nob.ma Città di Napoli [...], ms. XIII C 96, Biblioteca Nazionale di Napoli [1588 c.ca].

${ }^{3} \mathrm{O}$ colascione é um instrumento semelhante à teorba, mas com apenas 2 ou 3 cordas graves. 
Em uma imagem de I balli di Sfessania, por detrás da máscara de Scaramucia, percebemos um colascione e um aerofone com fole, ${ }^{4}$ provavelmente uma sordellina.

Fig. 2a - Balli di Sfessanìa / Scaramucia- Fricasso (detail), British Museum, $1861,0713.885$ e Fig. 2b - M. Mersenne, Harmonie universelle, sordellina

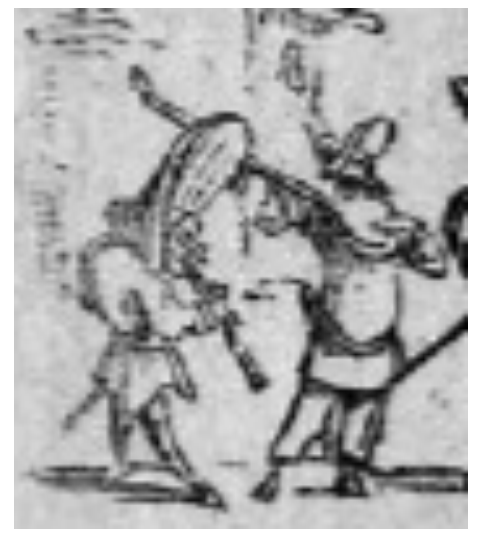

Fig. $2 a$

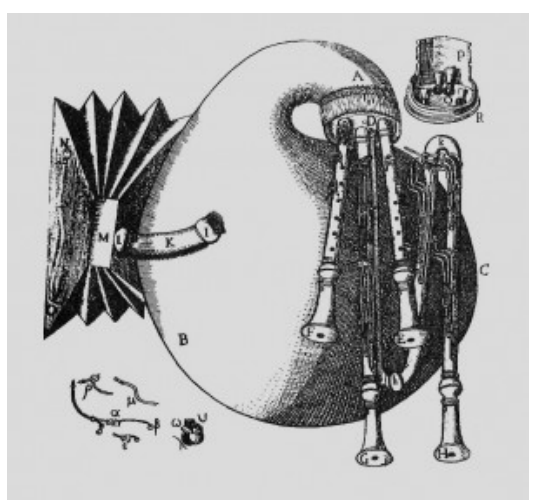

Fig. $2 b$

A sordellina era um instrumento de origem napolitana com um fole, similar à gaita de foles, mas sem sopro. ${ }^{5}$ Marin Mersenne refere-se ao instrumento em sua Harmonie Universelle, de $1636 .^{6}$

Sobrevivem hoje músicas de sfessanie no manuscrito Libro per scriver l'intavolatura per sonare sopra le sordelline, de Giovanni Lorenzo Baldano, de 1600. Certamente algumas destas músicas foram utilizadas em comédias, como sugere a Sfesanìa di Pascariello, ${ }^{7}$ uma personagem napolitana da commedia

${ }^{4}$ Mauro Gioielli, I balli di Sfessanìa di Jacques Callot, Extra, 29 gennaio 2011 (XVIII), n. 3 , p. 17-18; e Id. 5 febbraio 2011 (XVIII), n. 4, p. 17-1.

5 Sobre a sordellina, ver: Barry O'Neill, The Sordellina, a Possible Origin of the Irish Regulators, The Seán Reid Society Journal, Vol. 2, November 2001.

${ }^{6}$ Marin Mersenne, L'Harmonie universelle, Paris, Sébastien Cramoisy, 1636, II, p. 293-294.

7 Giovanni Lorenzo Baldano, Libro per scriver l'intavolatura per sonare sopra le sordelline, Savona, ms,1600, Fac-símile do manuscrito e estudo introdutório editado por Maurizio Tarrini, Giovanni Farris, John Henry van der Meer, Savona, Associazione Ligure per la Ricerca delle Fonti Musicali - Editrice Liguria, 1995 (Studi e Fonti per la Storia della Musica in Liguria, 2), música gravada no CD Lirum Li Tronc. Sordellina Colascione Buttafuoco Renaissance in Naples, Stradivarius, STR 33741. 
dell'arte. É notável que as músicas em questão estejam escritas em tablatura, tipo de escrita utilizada para os instrumentos de corda.

Fig. 3 - Giovanni Lorenzo Baldano, Libro per scriver l'intavolatura per sonare sopra le sordelline, Savona, ms, 1600.

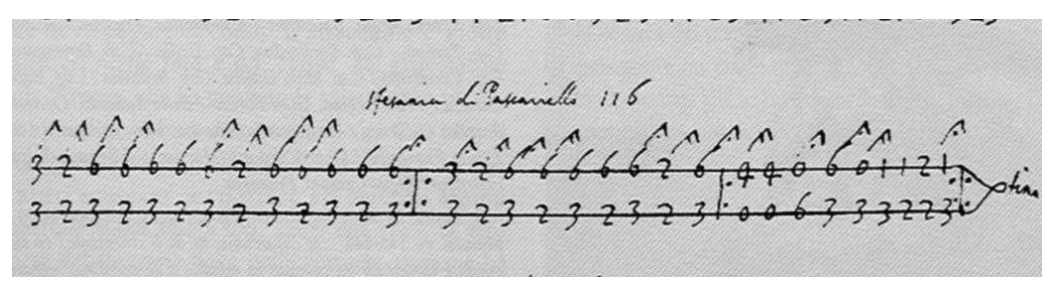

\section{As commedie di maschere e a música em Roma e arredores, o início do Seiscentos}

As commedie di maschere (chamadas também de commedie degli istrioni) eram normalmente dirigidas a um público popular, frequentemente por causa de sua linguagem licenciosa e desbocada. Por tal motivo, em geral, as comédias tinham vida mais difícil em Roma - cidade do papa - do que em outras cidades italianas, como Veneza, Modena, Bolohna, Nápoles, mesmo se fossem frequentemente bem recebidas pelos nobres da cidade eterna.

Fig. 4 - Balli di Sfessanial Cap. Cardoni - Maramao, British Museum, 1861,0713.875

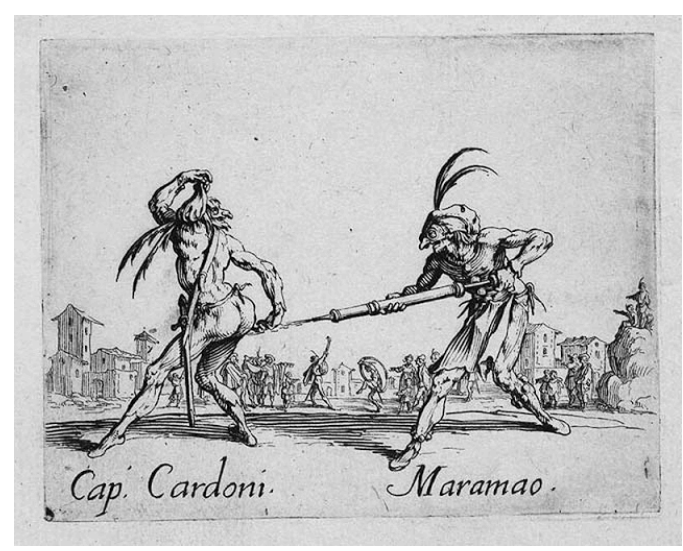


Uma vintena de textos impressos de commedie di maschere que circularam em Roma na primeira metade do Seiscentos, declaram explicitamente a presença de partes musicais. $^{8}$

Particularmente, entre os anos 1617-20, são publicadas as comédias com intermezzi musicais do dramaturgo, ator, músico e pintor, Giovanni Francesco Briccio (nascido e morto em Roma, entre 1579 e 1645), conhecido também como Giovanni Francesco del Leuto ${ }^{9}$ (do alaúde), como vemos na tabela seguinte:

Tabela I

\begin{tabular}{|c|c|c|c|c|c|c|}
\hline $\begin{array}{c}\text { Ano de } \\
\text { representação }\end{array}$ & $\begin{array}{c}\text { Local de } \\
\text { representação }\end{array}$ & Título & Dedicatória & $\begin{array}{c}\text { Local de } \\
\text { publicação da } \\
\text { obra }\end{array}$ & $\begin{array}{c}\text { Presença } \\
\text { declarada de } \\
\text { música }\end{array}$ & $\begin{array}{c}\text { Localização e } \\
\text { número da } \\
\text { fonte }^{10}\end{array}$ \\
\hline 1617 & Mazzano? & $\begin{array}{l}\text { Pantalon } \\
\text { Imbertonao }\end{array}$ & $\begin{array}{l}\text { Francesco Biscia } \\
\text { romano signore } \\
\text { di Mazzano }\end{array}$ & $\begin{array}{l}\text { Viterbo, } \\
\text { Discepoli }\end{array}$ & $\begin{array}{l}\text { Não, mas a } \\
\text { música é } \\
\text { declarada na } \\
\text { re-ed. de } \\
1619\end{array}$ & $\begin{array}{l}\text { Rn, } 34 . \\
\text { 1.G. } 16.6\end{array}$ \\
\hline 1619 & Mazzano? & $\begin{array}{l}\text { Pantalon } \\
\text { innamorao }\end{array}$ & $\begin{array}{l}\text { Francesco Biscia } \\
\text { romano signore } \\
\text { di Mazzano }\end{array}$ & Viterbo & $\begin{array}{l}4 \text { intermedi } \\
\text { musicali. }\end{array}$ & $\begin{array}{l}\mathrm{Rn}, \\
34.1 . G .19 .4\end{array}$ \\
\hline 1619 & $?$ & $\begin{array}{l}\text { La ventura di } \\
\text { Zanne e } \\
\text { Pascariello }\end{array}$ & $\begin{array}{l}\text { Luca De Carli } \\
\text { da Cottanello } \\
\text { (pseudônimo } \\
\text { do mesmo } \\
\text { autor) Roma } 15 \\
\text { dic } 1618\end{array}$ & Viterbo & $\begin{array}{l}5 \text { atos e } 4 \\
\text { intermedi “a } \\
\text { chi piacesse } \\
\text { di farli, tanto } \\
\text { apparenti, } \\
\text { come } \\
\text { musicali”. }\end{array}$ & $\begin{array}{l}\text { Rc, Comm. } \\
229 / 2\end{array}$ \\
\hline \begin{tabular}{|l|}
1620 \\
Já publicada 9 \\
anos antes em \\
Orvieto
\end{tabular} & $?$ & $\begin{array}{l}\text { La giudiata in } \\
\text { aria da } \\
\text { zingarate con } \\
\text { un norcino } \\
\text { che la } \\
\text { beffeggia }\end{array}$ & sem dedicatória & $\begin{array}{l}\text { Ronciglione } \\
\text { Vendida em } \\
\text { Roma, Praça } \\
\text { Navona, } \\
\text { insegna della } \\
\text { Lupa (loja } \\
\text { com um signo } \\
\text { de lobo) }\end{array}$ & $\begin{array}{l}\text { Alguns textos } \\
\text { eram talvez } \\
\text { musicados } \\
\text { (ottava, } \\
\text { madrigale, } \\
\text { canzonetta } \\
\text { pastorale) }\end{array}$ & $\begin{array}{l}\text { Rvat, Capp V } \\
684\end{array}$ \\
\hline
\end{tabular}

${ }^{8} \mathrm{O}$ elenco das commedie di maschere que recolho indicações das partes musicais faz parte do trecho de um inventário sobre texto de Saverio Franchi, Drammaturgia romana: Repertorio bibliografico cronologico dei testi drammatici pubblicati a Roma e Lazio, Secolo XVII. Roma: Edizioni di Storia e Letteratura, 1988.

${ }_{9}^{9}$ Michel, 1972. Bricci (Briccio, Brissio, Brizio), Giovanni, Dizionario Biografico degli Italiani, 14.

10 Todas as comédias estão conservadas junto à biblioteca romana, como segue: Rn = Biblioteca Nazionale; $\mathrm{Rc}=$ Biblioteca Casanatense; Rvat = Biblioteca Apostolica Vaticana (Città del Vaticano). 
Pode-se notar como diversas comédias, até o final dos anos '40 do século XVII, não foram impressas em Roma (provavelmente por causa da hostilidade dos papas em relação a tais espetáculos), mas vieram à luz principalmente em Viterbo, favoritos do nobre mecenas Francesco Biscia. Não obstante, estes textos certamente circularam em Roma como mostra a dedicatória de La ventura di Zanne e Pascariello e o anúncio de venda na Praça Navona (uma das praças mais importantes da cidade eterna) de La giudiata in aria da zingarate. Além disto, Briccia e Biscia eram romanos e é compreensível que favorecessem a presença destes textos em sua cidade de origem, a mais importante do território. A venda de comédias na Praça Navona foi um constume nos anos posteriores (podemos ver nas Tabelas seguintes).

Em Pantalon innamorao, de 1619, encontramos o retrato de Briccio ${ }^{11}$. Esta comédia tinha quatro intermedi musicais; tratava-se da re-edição de Pantalon Imbertonao, de $1617^{12}$ que, ao contrário, não apresentava nenhuma indicação sobre música. Lamentavelmente, não é possível localizar hoje referências às músicas dos intermedi, mas é provável que Briccio tivesse composto também a música, além do texto da comédia.

Fig. 4 - G. F. Briccio, Pantalon innamorao, retrato do autor, p. 2; detalhe da página 3.
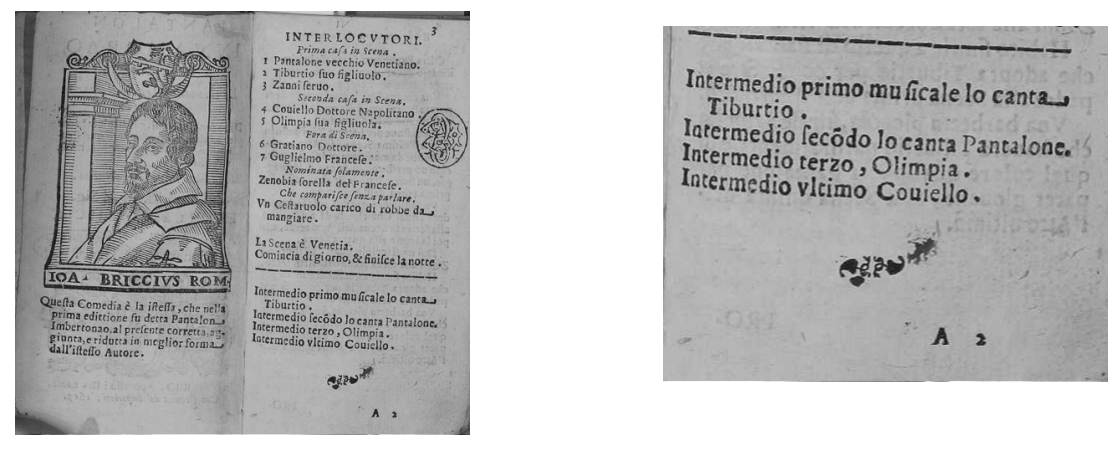

\footnotetext{
11 Pantalon innamorao: commedia de Giovanni Briccio romano con piacevoli e ridicolose scene si mostra spesso esser vero quel proverbio, Che un disordine accomoda un'ordine, Viterbo, Discepoli, 1619. Nova edição, dedicada a Francesco Biscia, romano, signore de Mazzano, emblema que mostra um dragão. No texto se encontra 18 pequenas figuras xilografadas. O retrato do autor está na pag. 2 Cfr. Franchi, cit., p. 101-102.

${ }^{12}$ Ver Tabela I.
} 
Ao final do I Ato, no primeiro intermedio de Pantalon innamorao, Tiburtio cantava um Madrigale in musica sopra Tiorba, o qual começa com cinco notas, ré fá mi sol lá”, do título Refammi sol Amor quel che mi hai tolto, portanto, um soggetto cavato.

Fig 5 - Giovanni Francesco Briccio, Pantalon innamorao, fim do I ato.

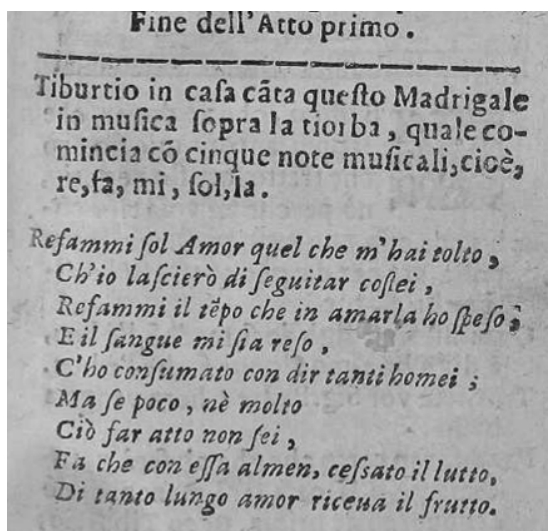

No segundo intermedio, Pantalone cantava ao alaúde a canção Pantalon innamorao. No terceiro, Olimpia exibia-se com o madrigal Poco mi giova amore ao gravecimbalo (cravo). No quarto intermezzo, Coviello cantava a canção Belle Zitte gratiose acompanhando-se à chitarra spagnola.

A comédia posterior de Briccio, La ventura di Zanne e Pascariello, foi escrita em Roma, em 1618, e publicada em $1619^{13}$. Era possível recitar em uma Mascherata, com em um sarau, ou em um festim. A comédia La ventura di Zanne e Pascariello possuía quatro intermedi, com ou sem música, ad libitum, sobre os quais não encontrei outras referências. Como sabemos, ainda hoje sobrevivem muitas músicas italianas para Mascherate: temos, por exemplo, a música de Andrea Gabrieli, reeditada em 1601, em que aparecem as personagens Pantaloni, dottori bergamaschi, contadini, greci studiosi, tedeschi; ${ }^{14}$ algumas Mascherate

\footnotetext{
${ }^{13}$ Rc, Comm. 229/2. Franchi, cit., p. 99.

${ }^{14}$ Mascherate [...] a tre, quattro, cinque, sei, et otto voci di Andrea Gabrieli. Novamente stampate, et date in luce. Venezia: A. Gardano, 1601.
} 
fiorentine, de $1613 ;^{15}$ e ainda temos a música de Marco da Gagliano e di Gastoldi para as Mascherate.

Em 1620, ainda de Briccio, é publicado La giudiata in aria da zingarate con un norcino che la beffeggia: frottola piacevole e bella. ${ }^{16}$ Aqui convergem dois gêneros teatrais, a giudiata e a zingarata, muito comuns em Roma dos séculos XVI e XVII. Nas giudiate, frequentemente representadas em vagões itinerantes, caçoava-se dos judeus, enquanto no segundo tipo, os zingare frequentemente interagiam com a figura do carniceiro, açougueiro da Umbria, região da Itália central. A giudiata, que apresentava diversos cantos populares, era um gênero muito apreciado da plebe romana. ${ }^{17}$

Em La giudiata in aria da zingarate encontramos o strambotto Che debbo far? Che mi consigli Amore? Como é sabido, o texto de Che debb'io far? Che mi consigli Amore? de Francesco Petrarca foi utilizado por Giovanni Pierluigi da Palestrina em um de seus famosos madrigais, mas tenho dúvidas de que na giudiata se cantasse justamente o madrigal palestriniano. Além disso, a definição de strambotto exige um texto poético de oito versos (ottava), coisa que não corresponde ao poema de Petrarca, estruturado sobre estrofes de onze versos cada uma. É possível, no entanto, que o cantor-ator se exibisse com uma paródia do texto de Petrarca (e talvez também com o madrigal de Palestrina) adaptando aquele(s) modelo(s) ao esquema popular do strambotto.

Não tivemos nenhum contato com as outras músicas da giudiata, como a ottava "alla norcina," O que sia benedetto sa fantella, e a canzonetta pastorale, Oh mia cara Amaranta.

As formas musicais como a canzonetta, o strambotto, a ottava, em voga até um ou dois séculos anteriores na Itália, eram, no entanto, ultrapassados nos

\footnotetext{
15 Descrizzione della barriera e della mascherata fatte in Firenze a XVII e a XI. Firenze: Sermartelli Bartolommeo e F.lli, 1613,

${ }^{16}$ Rvat. Capp V 684 já publicada nove anos antes, em Orvieto.

17 As giudiate eram de hábito recitadas sobre um carro de boi ornado de ramos onde se cantava "in varie maniere, tutte particolari del volgo, e coll'accompagnamento di tali suoni, che non sono sconvenevoli a tutto il resto; e pure, allorchè si fanno, o giorno, o notte, che sia, infinito popolo si tirano appresso, e con estremo godimento, e riso s'ascoltano", cfr. Giovanni Mario Crescimbeni, Comentarj [...] intorno alla sua Istoria della Volgar Poesia. Roma: Antonio de’ Rossi alla Piazza di Ceri, 1702, I, p. 199.
} 
anos de 1617-1620; mesmo o madrigal começava, nesta época, a tornar-se uma forma obsoleta. Creio que tal 'arcaísmo' musical fosse ligado às antigas raízes da commedia dell'arte e que tais formas musicais fossem conservadas também por causa do influxo da música popular.

Em 1624, em Orvieto e, em 1625, em Viterbo (ver Tabela II), foi publicada La vendetta amorosa de Vergilio Verucci ${ }^{18}$, em que personagens da comédia (como Ricciolina serva, Zanni Hoste, Coviello, etc.) misturavam-se aos coros de pastores de ninfas. Na comédia, diversos instrumentos executavam sinfonias e concerti. ${ }^{19}$ A presença de personagens pastorís e da orquestra transformava esta comédia em um produto destinado ao público culto.

Tabela II

\begin{tabular}{|c|c|c|c|c|c|c|c|}
\hline Ano & Lugar & Autor & Título & Dedicatória & $\begin{array}{l}\text { Lugar de } \\
\text { publicação, } \\
\text { editor }\end{array}$ & $\begin{array}{c}\text { Presença de } \\
\text { música }\end{array}$ & Localização \\
\hline $\begin{array}{l}1625 \\
\text { á } \\
\text { apresentada } \\
\text { em Orvieto } \\
\text { em } 1624\end{array}$ & Roma? & $\begin{array}{l}\text { Vergilio } \\
\text { Verucci dottor } \\
\text { di Legge e } \\
\text { Accademico } \\
\text { Intrigato di } \\
\text { Roma }\end{array}$ & $\begin{array}{l}\text { La } \\
\text { vendetta } \\
\text { amorosa }\end{array}$ & $\begin{array}{l}\text { Giovan } \\
\text { Battista } \\
\text { Olgiati } \\
\text { marchese di } \\
\text { Poggio } \\
\text { Catino }\end{array}$ & \begin{tabular}{|l||} 
Viterbo, \\
Agostino \\
Discepoli \\
si vendono a \\
Piazza Navona \\
al Morion \\
d'oro
\end{tabular} & $\begin{array}{l}\text { Si, strumenti } \\
\text { musicali “di } \\
\text { più sorte da } \\
\text { far sinfonie, e } \\
\text { conserti }\end{array}$ & $\begin{array}{l}\text { Rn, } 35.9 . \\
\text { I.7.4 }\end{array}$ \\
\hline 1636 & & $\begin{array}{l}\text { Melchior Bossi } \\
\text { da Cori }\end{array}$ & $\begin{array}{l}\text { Lo } \\
\text { Gnaccara }\end{array}$ & & \begin{tabular}{|l|} 
Orvieto, \\
Rinaldo Ruuli, \\
vendita a \\
Piazza Navona \\
alla Palla \\
d'Oro
\end{tabular} & $\begin{array}{l}\text { Robe da } \\
\text { provvedersi: } \\
\text { tre vestiti, due } \\
\text { facchini, un } \\
\text { chitarrino. }\end{array}$ & $\begin{array}{l}\mathrm{Rn}, \\
34,1 . G \cdot 20.7\end{array}$ \\
\hline 1638 & Roma & $\begin{array}{l}\text { Gio. Battista } \\
\text { Pianelli } \\
\text { "romano" }\end{array}$ & $\begin{array}{l}\text { Li falsi } \\
\text { mori }\end{array}$ & $\begin{array}{l}\text { Monsignor } \\
\text { Ferrante } \\
\text { Cesarino }\end{array}$ & \begin{tabular}{|l|} 
Roma, Grign \\
vendita a \\
Piazza Navona \\
alla Palla \\
d'Oro.
\end{tabular} & $\begin{array}{l}\text { Madrigali da } \\
\text { cantarsi }\end{array}$ & $\begin{array}{l}\text { Rn, } \\
34.1 . E .6 .3\end{array}$ \\
\hline
\end{tabular}

Estas maschere e a presença de muitos instrumentos nos fazem pensar na companhia do célebre ator Francesco Gabrielli, que frequentemente interpretou a máscara de Scapin, embora não saibamos se Gabrielli, intérprete e inventor de diversos instrumentos musicais, ativo em diversas cidades do norte da Itália e da

\footnotetext{
${ }^{18}$ Virgilio Verucci já havia publicado La moglie superba. Viterbo: 1621.

${ }^{19}$ Virgilio Verucci, La vendetta amorosa. cfr. Saverio Franchi, Drammaturgia romana: p. 142.
} 
França, ${ }^{20}$ apresentou-se efetivamente em Roma naquele ano. Seu retrato, feito por Carlo Biffi, o apresenta circundado de instrumentos musicais muito curiosos, entre os quais, a chitarra-cetra a tre manichi, retratada à direita, em baixo, ${ }^{21}$ uma teorba em forma de "lira" grega à esquerda, embaixo, ${ }^{22}$ uma sordellina à esquerda.

Fig. 6 - Carlo Biffi, Retrato de Francesco Gabrielli (1588 - 1636)

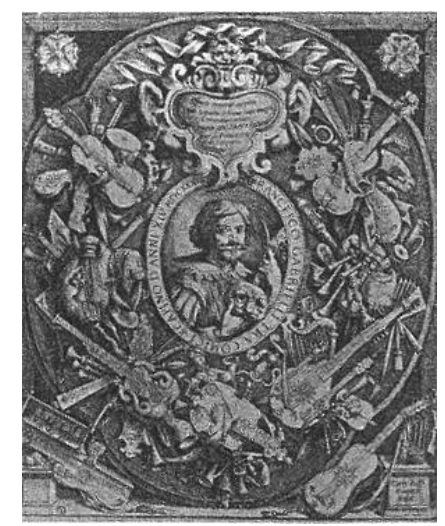

No Libro di piume, escrito por Dionisio Minaggio, em Milão, em 1618, ${ }^{23}$ aparecem imagens curiosas de Carlo Biffi e outros atores de sua companhia. Scapin faz uma serenata à dama Spineta com um instrumento de cordas com braço. À sua direita, pendurado em uma árvore, vemos um cornetto, talvez um oboé, dois alaúde, um violino, um chitarrone e outros instrumentos de uso popular, provavelmente uma sordellina e dois buttafuoco. ${ }^{24}$

\footnotetext{
20 Teresa Megale, Gabrielli Francesco detto Scapino o Scappino, in Dizionario Biografico degli Italiani, vol. 51, 1998.

${ }^{21}$ Sobre este instrumento e a sua presença no retrato ver: Patrizio Barbieri, Musiche e strumenti "alla greca" nel Seicento taliano, in Francesco Buti tra Roma e Parigi: diplomazia, poesia, teatro Atti del Convegno Internazionale di studi, Parma 12-15 dicembre 2007 a cura di Francesco Luisi. Roma: Torre d'Orfeo, 2009, p. 350-352.

${ }^{22} \mathrm{Um}$ instrumento muito similar é hoje conservado no Museu Civico Medieval de Bolonha, John Henry van der Meer, Strumenti musicali europei del Museo Civico Medievale di Bologna. Bologna: Nuova Alfa Editoriale, 1993, p. 108, scheda 106, Tiorba in forma di kithara, e p. 183 tavola a colori.

${ }^{23}$ Conservado hoje na McGill University Library, Montreal.

${ }^{24}$ O buttafuoco é um instrumento de cordas "batido." cfr. der Meer, Alcune considerazioni intorno al buttafuoco in Giovanni Lorezo Baldano, Libro per scrivere l'intavolatura.
} 
Fig. 7 - Dionisio Minaggio Libro di piume, Milão, 1618, f. 110, McGill University Library, Montreal

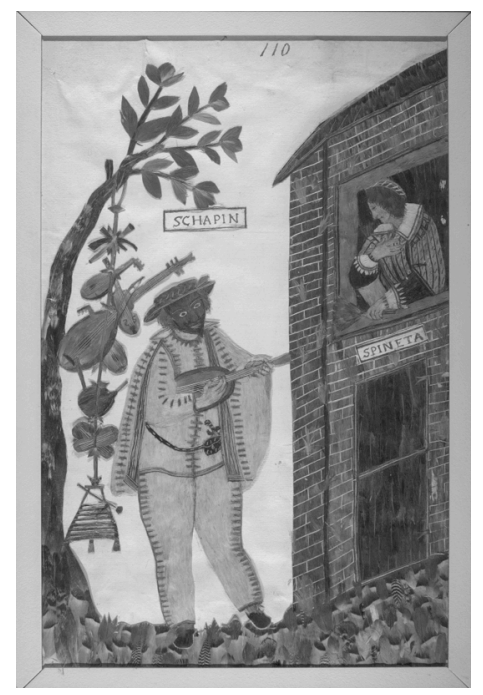

Em outra imagem do Libro di piume vemos Trastulo que faz uma serenata a Ricolina com um colascione, enquanto dança.

Fig. 8 - Dionisio Minaggio Libro di piume, Milão, 1618, f. 104, McGill University Library, Montreal

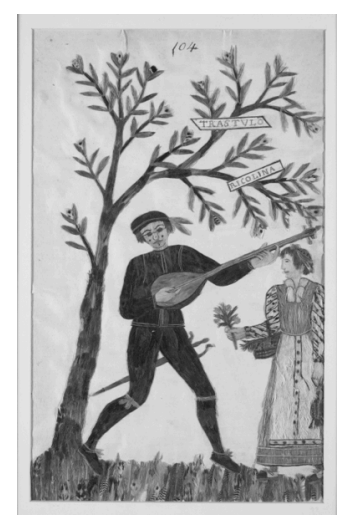


Voltemos à cronologia das comédias que circularam em Roma (Tabela II). Em Lo Gnaccara de Melchior Bossi, de 1636, há indicação de um chitarrino; não há nenhuma outra indicação sobre música. ${ }^{25}$

Em Li falsi mori, de Gio. Battista Pianelli, ${ }^{26}$ de 1638, cantava-se diversos madrigais. O primeiro, L'Empio ch'ancide l'alme de Giovani Martino Longo deveria ser cantado no princípio do primeiro ato (da cantarsi nel principio del primo atto), seguido por $O$ quest'Amor fallace, de Giovanni Santi De Andreis (ao final do I ato), Gite, o fatali amanti, de Francesco Nocera da San Tomaso (fim do II ato), Quelle facelle ardenti, de Francesco Thidei (fim do III) e Cessi, cessi, o Castoro de Guid'Ubaldo Abbatini (fim do IV). Infelizmente não encontrei traços destes madrigais nem dos compositores citados; fato que nos leva a pensar que os autores não fossem músicos profissionais, mas os próprios atores das comédias que compunham e executavam suas próprias peças.

Parece-me importante recordar que, em 1639, Giulio Rospigliosi introduziu personagens da commedia dell'Arte no intermezzo La fiera di Farfa, com música de Marco Marazzoli, ao final do segundo ato do melodrama Chi soffre speri de Virgilio Mazzocchi. A apresentação ocorreu no Carnaval, no Palácio Barberini alle Quattro Fontane. ${ }^{27}$ Tratava-se de uma mescla rara entre melodrama e commedia dell'arte, em que esta última possuía música do começo ao fim e misturava as personagens, idiomas e estilos, com os traços de um gênero mais "nobre", o melodrama.

\section{Roma, segunda metade do Seiscentos. Os príncipes Ottoboni.}

Por volta da metade do século, em Roma, assistimos a uma redução na produção de commedie con maschere, o primeiro texto com intervenções musicais

\footnotetext{
${ }^{25}$ Melchior Bossi, Lo Gnaccara. Orvieto: Rinaldo Ruuli, 1636. A primeira edição da comédia foi feita em Veneza, em 1637. A cena da comédia era ambientada em Roma. "Robe da provvedersi: tre vestiti, due facchini, un chitarrino".

${ }^{26}$ Giovanni Battista Pianelli, Li falsi mori. Roma: Grignani, 1638.

27 Sobre o tema ver: Lorenzo Bianconi - Thomas Walker. Dalla "Finta pazza" alla "Veremonda": storie di Febiarmonici. Rivista italiana di musicologia, X, 1975, p. 223-227.
} 
que conhecemos hoje é Non v'ha mel senza mosche, de Tomaso Santagostini, com um prólogo musical em que cantam Orbo pitocco e Gelosia, a peça foi publicada em 1671 (Tabela III). ${ }^{28}$ Em seguida, encontramos mascherate em versos para cantar, ${ }^{29}$ comédias com prólogos e intermezzi musicais, e balli. ${ }^{30}$

Tabela III

\begin{tabular}{|c|c|c|c|c|c|c|}
\hline Ano & Autor & Título & Dedicatória & $\begin{array}{l}\text { Local de } \\
\text { publicação, } \\
\text { editor }\end{array}$ & $\begin{array}{l}\text { Presença de } \\
\text { música }\end{array}$ & Localização \\
\hline 1671 & $\begin{array}{l}\text { Sottogisnio } \\
\text { Manasta } \\
{[\text { Tomaso }} \\
\text { Santagostini], }\end{array}$ & $\begin{array}{l}\text { Non v'ha mel } \\
\text { senza mosche }\end{array}$ & $\begin{array}{l}\text { Girolamo Velli } \\
\text { del Cairo nel } \\
\text { Monferrato }\end{array}$ & $\begin{array}{l}\text { Roma, Tizzoni } \\
\text { Jà publicada em } \\
\text { Milão e Bolonha. } \\
\text { Vendida na Praça } \\
\text { Navona, } \\
\text { Francesco } \\
\text { Lupardi Libraro. }\end{array}$ & $\begin{array}{l}\text { Prologo per } \\
\text { musica: Orbo } \\
\text { pitocco e Gelosia }\end{array}$ & $\begin{array}{l}\text { Rn, 34, } 1 . \\
\text { G.29.1 }\end{array}$ \\
\hline \begin{tabular}{|l|}
$1675-$ \\
$80]$
\end{tabular} & & $\begin{array}{l}\text { Mascherata } \\
\text { piacevole }\end{array}$ & & $\begin{array}{l}\text { Viterbo, Pietro } \\
\text { Martinelli, } \\
{[1675-80] .}\end{array}$ & $\begin{array}{l}\text { Mascarada com } \\
\text { versos para } \\
\text { cantar. }\end{array}$ & $\begin{array}{l}\text { Rn, } 69.6 . \\
\text { A. } 54.8\end{array}$ \\
\hline 1676 & $\begin{array}{l}\text { Pietro } \\
\text { Francesco } \\
\text { Minacci } \\
\text { fiorentino } \\
\text { Accademico } \\
\text { Apatista }\end{array}$ & // Bernardone & $\begin{array}{l}\text { Maffeo } \\
\text { Barberini } \\
\text { principe di } \\
\text { Palestrina, }\end{array}$ & $\begin{array}{l}\text { Roma } \\
\text { Michel'Ercole, } \\
\text { vendido em } \\
\text { Roma na Praça } \\
\text { Madama, loja de } \\
\text { Francesco Leone } \\
\text { libraro. }\end{array}$ & $\begin{array}{l}\text { Ballo ao final do } \\
\text { terceiro ato. }\end{array}$ & $\begin{array}{l}\text { Rn, 34, } 1 . \\
G .29 .3\end{array}$ \\
\hline 1676 & $\begin{array}{l}\text { Gio Battista } \\
\text { Salviati }\end{array}$ & I/ Tesoro & $\begin{array}{l}\text { Camillo } \\
\text { Pelandini }\end{array}$ & $\begin{array}{l}\text { Roma, Francesco } \\
\text { Tizzoni vendido } \\
\text { em Roma; } \\
\text { Francesco Leone } \\
\text { libraro; praça } \\
\text { Madama. }\end{array}$ & Prologo musical & $\begin{array}{l}\mathrm{Rn}, 34.1 . \\
\mathrm{G} .30 .3 .\end{array}$ \\
\hline
\end{tabular}

28 [Tomaso Santagostini], Non v'ha mel senza mosche. Roma: Tizzoni, 1671, já impressa em Milão e em Bolonha. O autor usava o pseudonimo "dottor Sottogisnio Manasta", 3 atos em prosa.

${ }^{29}$ Anonimo, Mascherata piacevole "da recitarsi il Carnevale composta nuovamente di un Pulcinella e due Furbi". Viterbo: Pietro Martinelli, [1675-80]; Pietro Francesco Minacci, II Bernardone. Roma: Michel'Ercole, 1676; Giovanni Battista Salviati, II Tesoro. Roma: Francesco Tizzoni, 1676.

${ }^{30}$ Neste período, em outra cidade da península italiana circulavam diversas comédas de máscaras com música, como exemplo: Domenico Balbi, I/ Lippa overo El pantalon burlao, comedia [!] honestissima piena di sottili intentioni e tanto per rappresentarla quanto anco per semplicemente legerla [!] tutta ridicolosa. Con alcune composizioni accademiche in prosa e in rima ad essa concernenti in questa seconda impressione accresciute, intrecciate con Ariette musicali da cantarsi di D. Domenico Balbi. Venetia: Giacomon Dedini, 1680. 
Na última década, em Roma, os espetáculos de mascherate começaram a gozar de melhor fortuna. Ao final de 1689, o velho cardeal Pietro Vito Ottoboni, de família nobre veneziana, foi eleito papa com o nome de Alessandro VIII. Por causa de sua paixão pelos espetáculos e pela música, foi apelidado de il papa Pantalone. Apenas eleito, Alessandro VIII nomeou como cardeal seu sobrinho neto Pietro Ottoboni, que na época tinha apenas 22 anos. Pietro, que era também dramaturgo, tornou-se um dos mecenas mais importantes de Roma, graças também à fortuna que acumulava em função de seu cargo. Na sua sede, o Palazzo della Cancelleria, o cardeal Pietro e seu pai, o príncipe Antonio, promoveram numerosos espetáculos teatrais, muito elogiados pelas crônicas. Diversos estudos têm sido publicados sobre o mecenato musical deste cardeal, ${ }^{31}$ mas nenhum, até este momento, ocupou-se das comédias mascherate e de sua relação com a

${ }^{31}$ Hans Joachim Marx. Die Musik am Hofe Pietro Kardinal Ottoboni unter Arcangelo Corelli, Analecta musicologica, V (1968), p. 104-177, trad. La musica alla corte del cardinale Pietro Ottoboni all'epoca di Corelli in La musica e il mondo. Mecenatismo e committenza musicale in Italia tra Quattro e Settecento a c. di Claudio Annibaldi. Bologna: II Mulino 1993, p. 85-107; Mercedes Viale Ferrero. Antonio e Pietro Ottoboni e alcuni melodrammi da loro ideati o promossi a Roma in Venezia e il melodramma nel Settecento a c. di Maria Teresa Muraro. Firenze: Olschki 1978, p. 287; Maria Letizia Volpicelli, II Teatro del Cardinale Ottoboni al Palazzo della Cancelleria in II teatro a Roma nel Settecento, a cura del Servizio Attività Culturali dell'Istituto dell'Enciclopedia Italiana, Roma, Istituto della Enciclopedia Italiana, 1989 (Biblioteca internazionale di cultura, 21), II, p. 681-782; Stefano La Via, II cardinale Ottoboni e la musica: nuovi documenti (1700-1740), nuove lettere ed ipotesi in Intorno a Locatelli. Studi in occasione del tricentenario della nascita di Pietro Antonio Locatelli (1695-1764) a cura di Albert Dunning, Lucca, LIM, 1995, I, p. 319526 e relativa bibliografia; Teresa Chirico, L'inedita serenata alla regina Maria Casimira di Polonia: Pietro Ottoboni committente di cantate e serenate (1689-1709), in AAVV. La serenata tra Seicento e Settecento. Musica, poesia, scenotecnica a cura di Nicolò Maccavino, Atti del Convegno Internazionale di Reggio Calabria, p. 16-17 maggio 2003, Reggio Calabria, Laruffa Editore, 2007, vol. II, p. 397-449; Teresa Chirico, Strumenti a corde e a fiato e strumentisti in casa Ottoboni all'epoca di Händel a Roma in $A A V V$., Georg Friedrich Händel in Rom. Beiträge Internationalen Tagung am Deutschen Historischen Institut in Rom a cura di Sabine Ehrmann-Herfort e Matthias Schnettger, Atti del Convegno Internazionale di Roma, 17-20 ottobre 2007, Analecta musicologica, vol. 44 (2010), Kassel, BärenreiterVerlag, p. 291-306; Teresa Chirico, Noticias inéditas sobre instrumentos de teclado, constructores y musicos en Roma, en la corte del principe cardenal Pietro Ottoboni entre los anos 1689 y 1719. in AAVV. Domenico Scarlatti en España a cura di Luisa Morales. Atti del Convegno Internazionale di Garrucha, 2006-2007, Garrucha, Leal, 2009, p. 143-159; Teresa Chirico, Harpsichords and Harpsichords makers employed in Rome by Cardinal Pietro Ottoboni and his Father Antonio, The Galpin Society Journal, vol. LXII (2009), p. 101-115; Teresa Chirico, La vicenda di Adonìa nelle opere di Girolamo Frigimelica Roberti (1695) e Pietro Ottoboni (1699). Un unico progetto ottoboniano?, in AAVV., Musikstadt Rom. Geschichte Forschung Perspektiven. Beiträge der Tagung Rom, Atti del Convegno internazionale a cura di Markus Engelhardt, Roma, 28-30 settembre 2004 Analecta musicologica, vol. 45 (2011) Kassel, Bärenreiter, p. 218-262. 
música. As informações a este respeito encontram-se em documentos inéditos, hoje conservados na Biblioteca Apostolica Vaticana da Cidade do Vaticano. ${ }^{32}$

Os príncipes Ottoboni, a partir de dezembro de 1689, possuíam camarotes nos teatros romanos Capranica e Della Pace (chamado delli Saltainbanchi), onde eram apresentadas as commedie con maschere. Os aluguéis dos camarotes estão documentados pelo menos até o ano de $1694 .^{33}$

No carnaval de 1690, no teatro do Palazzo della Cancelleria, apresentaram-se alguns istrioni, talvez os mesmos que se exibiram no Teatro Pace. ${ }^{34}$ Os príncipes, evidentemente satisfeitos com as apresentações, ofereceram generosas gratificações aos cômicos Filippo Rope (dito Pantalone), Lucha Richiara, Antonio Nardacci, Marco Antonio Zanetti (ou Zannetti), ${ }^{35}$ quem interpretava

32 Biblioteca Apostólica Vaticana de agora em diante citada como I-R-vat. Todos os documentos citados fazem parte da Contabilidade Ottoboni; fica omitido esta informação por considerá-la subtendida. Reforço que a moeda em uso era o escudo (s.) e o baiocco (b.); m.ta = moeda; s.n.i = sem número inteiro, há fascículo não numerado.

33 I-R-vat., vol.13, n. 81, 18 dicembre 1689, "Conto delli lavori fatti da me M.[aest]ro Pasquale Tamburrini per servitio delli Palchetti al Teatro di Tor di Nona e per Capranica e per la Pace [...]"; vol. 14, n. 148: "A dì 29 [novembre 1689, ...] "Per haver dato al solaro appoggi di pelle rossa che fanno pelle n. 6 a b. 16 la pelle al teatro al Pace :96"; vol. 13, n. 158 , conta de 16 de fevereiro de 1690, "Memorie delli denari pagati à diversi per noli e porti di alcune robbe come per ordine del S. Fran.[cesc]o Niccoli maestro di Casa per serv.[i]tio di Sua Em.[inentissi]ma [...] e più per il nolo di tre sedie di damasco cremesino alla francese per il Teatro delli Saltaimbanchi alla pace con anche tre scabelletti per detto dalli 30 Xbre 1689 a tutto li 8 febb.o 1690 s.[cudo] 1"; vol. 14, n. 159: "A dì 7 detto [gennaio 1690] et altro per servizio delli palchetti al Teatro della Pace s. :40 rasi, sete e stoffe"; vol. 14, n. 163: "A dì primo gennaro 1690 Si è pagato a Salvator Torre rigattiero s. $40 \mathrm{~m}$. [one]ta per il nolo di quattro scabelletti di Punto francese per il Teatro della Pace per tutto il Carnevale s. 40"; vol. 14, n. 658: Conto di diversi lavori fatti da Mro Sebastiano Cartosi? Falegname [...] Palazzo della Cancelleria [...], f. int. 6: Lavori fatti per Teatro della Cancelleria e Pace; vol.29, s.n.int: "A dì 2 d.o [aprile 1694] s. otto b. 70 m.a pagati à Gio: Batt.a Boccaletti falegname per lavori fatti nel Teatro della Pace per Serv.[izi]o di S. [ua] Em.[inen]za s 8.70"; vol. 30, n. 61, 11 de janeiro de 1694 "Conto di lavori diversi di pitture per palchetti in diversi teatri, tra cui il Pace"; vol. 30, nn. int. 20 (assinatura de P. Ottoboni), 24, 28, aluguel de teatro à Pace do carnaval até junho de 1694; outros trabalhos, n. 200.

${ }^{34}$ Alguns documentos citando "Rastelli per li Abiti di Commedie" e "quattro orinali ordinari per le stanze dove si vestono li comici". I-Rvat, vol. 13, n. 158, conta de16 de fevereiro de 1690, "Memoria delli denari pagati à diversi per Noli e porti di alcune robbe come per ordine del S.[ignor] Fran.[cesc]o Piccoli mastro di Casa per servitio di Sua Em.ma [...] E più b. 30 m.ta spesi in 14 rampini per accomodare li Rastelli per li Abiti di Commedie s... 30"; vol. 13, n. 180, "Spese diverse [...] 1690 li 20 febbraio [...] E più per haver comprato quattro orinali ordinari per le stanze dove si vestono li comici s._20".

35 I-Rvat, vol. 13, n. 171, "Noi infrascritti habiamo ricevuto dal Sig.e Francesco Niccoli Mastro di casa [...] scudi trenta moneta sono per mancia che da l'Em.mo come Comici, questo dì 3 marzo 1690 et in fede lo Filippo Rope (?) detto Pantalone [altra grafia] io Lucha Richiara Mano Propria [altra grafia] Io Antonio Nardacci Mano Propria"; vol. 13, n. 
habitualmente o personagem de Truffaldino. Zannetti havia se apresentado em Modena, em 1688 e, depois do Carnaval romano de 1690, transferiu-se para o Norte da Itália junto com sua companhia. ${ }^{36}$ Não sabemos quais comédias foram representadas no Palazzo della Cancelleria, mas sabemos que naquele Carnaval apresentou-se o músico Antonio Bonazzi, sobre o qual não tenho nenhuma outra referência. ${ }^{37}$

Entre outubro e novembro de 1690, em Cancelleria, foram representadas outras comédias de istrioni com muitos espectadores e grande successo, como testemunham as crônicas da época. ${ }^{38}$ As comédias (como sabemos a partir dos documentos da Biblioteca Apostolica Vaticana) foram o Convitato di pietra, I/ finto Prencipe e La dama superba. Sobre esta última comédia não encontrei, infelizmente, nenhum documento. // finto pr[i]ncipe era talvez uma comédia de Carlo Ambrosi, publicada em Bolonha, em 1687, ou a de Santi Nicoletti que seria publicada em Brescia e Milão anos depois, em 1698. ${ }^{39}$ // convitato di pietra foi

108 "Note di pagamenti fatti per diversi [...] A dì 3 marzo s.di trenta m.a pagati alli comici del Teatro della Pace". vol. 13, n. 163, "Lista delle spese fatte da Benedetto Pastorelli M. [aest]ro di casa dell'Ecc. [ellentissi]mo Sig.r Pre[nci]pe D. Ant. Otth.[oboni] P[ad]rone per tutto il mese di marzo 1690 [...] A dì detto [7 marzo 1690] s. 15 pagati a Marco Antonio Zannetti Comico nell teatro della Pace per mancia data di ordine di S.E. Pren.[cip]e per r.[icevu]ta s. 15 [...]".

${ }^{36}$ Estas informações foram encontradas em uma carta de 10 de agosto de 1690, enviada da mesma companhia da Brescia: os atores, encontrando-se em dificuldades econômicas por causa dos rendimentos insuficientes, escreveram ao duque de Mantova pedindo para que ele enviasse dinheiro, se quisessem que eles fossem até Bolonha a seu serviço. Luigi Rasi, I comici italiani, biografia, bibliografia, iconografia, L-Z, II,1905, pp. 693-694; Carmelo Alberti. La scena veneziana nell'età di Goldoni. Roma: Bulzoni, 1990, p. 42 nota 52: Marco Antonio Zanetti interpretava Truffaldino; Vito Pandolfi, Siro Ferrone, La Commedia dell'arte: storia e testo, Vol. 51988.

${ }^{37}$ Em 25 março Pietro Ottoboni pagou uma gorgeta de 10 escudos a um músico, Antonio Bonazzi, e em 14 maio 6 escudos a diversos artistas (tais pagamentos foram feitos imediatamente depois aos atores cômicos: I-Rvat, vol 13, n. 108, "A dì 25 detto [marzo] d.ti diece moneta pag.ti ad Antonio Bonazzi musico per Mancie s. 10 [...] A dì 14 Mag. S.di sei m.a pag.ti a diversi artisti per Mancie s. 6".

38 Gloria Staffieri, Colligite fragmenta. La vita musicale romana negli Avvisi Marescotti (1683-1707). Lucca: LIM, 1990, p. 94-95.

${ }^{39}$ Sobre Pietro Ottoboni: I-Rvat, vol. 15, n. 599, anno 1690, 25 ott spesa per lumini "per servitio de i comici"; novembre, commedie dei comici: 7, 17 (Convitato di pietra), 22 ; dic: 22 per 2 sere, 25 II finto Prencipe (forse opera di Santi Nicoletti, II D. Antonio, o II birba finto principe, Brescia, et in Milano, Agnelli, 1698; oppure Carlo Ambrosi, Il finto principe comedia non meno ridicola, che honesta, Bologna, Longhi, 1687), il 29 La dama superba. Sobre Antonio Ottoboni: I-Rvat, vol. 21, n. 670, 26 nov 1690 "Conto e misura di alcuni lavori fatti da Mastro Sebastiano Carzoni fal.[egna]me per servizio dell'Ecc.mo Prencipe D. Antonio Ottoboni, nel Teatro del Palazzo della Cancelleria: Per avere attanato, stanato, e 
uma notável comédia de Giacinto Andrea Cicognini, publicada em 1663, que seria ainda re-editada em Veneza, em $1691,{ }^{40}$ o ano posterior à representação na casa Ottoboni. No texto surgem também personagens da commedia dell'arte, como Pantalone, Dottore, ou o servo Fichetto.

Fig. 9 - Giacinto Andrea Cicognini, II convitato di pietra, Venezia, Zamboni, 1691, frontispício e p. 40-41.

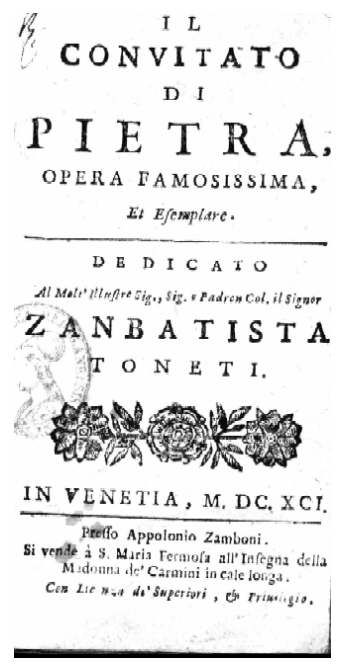

\begin{tabular}{|c|c|}
\hline 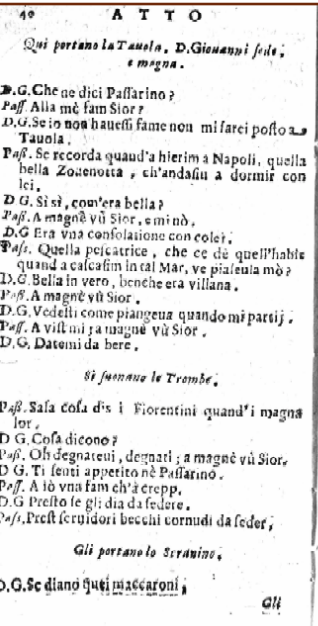 & 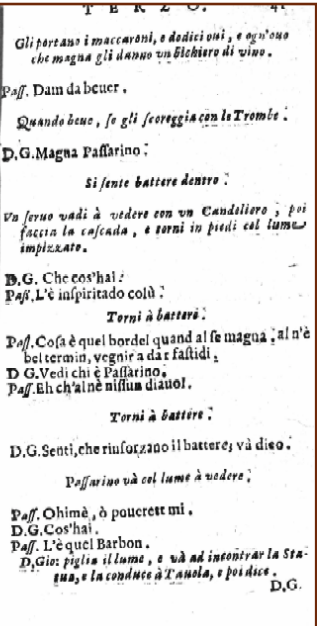 \\
\hline
\end{tabular}

Muito provavelmente a comédia feita no Palazzo di Ottoboni baseou-se neste libreto, ou sobre um canovaccio ${ }^{41}$ muito semelhante, obtido antes ainda da publicação da mesma comédia, em Veneza. Fato absolutamente plausível visto que o cardeal pertencia a uma poderosa família veneziana. No libreto encontramos intervenções musicais, por exemplo: no ato III, cena V, soam trompetes enquanto Don Giovanni está à mesa (p. 40-41, ver imagens); no ato III,

riposto d. [ett]o telone sud. [dett]o cinque volte quando si faceva la Comedia delli Istrioni e d[etti]. 4 homini s.3 [...] Per haver messo in opera le due scene con le casse per gl'Instrioni e serrato a mano 4 torcieri più volte $-10[\ldots]$ "

${ }^{40}$ Giacinto Andrea Cicognini, // convitato di pietra, Venezia, Zamboni, 1691. Como se pode notar, a comédia era uma variante do Convidado de piedra de Tirso de Molina; pela difusão de // Convitato come l'Ateista fulminato, cfr. Nicola Michelassi, La Finta pazza a Firenze: commedie 'spagnole' e 'veneziane' nel teatro di Baldracca (1641 - 1665), Studi secenteschi, 2000, p. 317-325.

${ }^{41}$ Enredo básico sobre o qual os atores improvisavam. 
cena VIII, a estátua do rei canta ameaçadoramente, enquanto Don Giovanni banqueteia-se.

Entre o final de 1690 e o início de 1691, no Teatro Tordinona de Roma, protegido e financiado pelo cardeal Ottoboni, foi representado, com pouco sucesso, o melodrama // Colombo, sobre a história do famoso navegador italiano, com texto do cardeal e música de Bernardo Pasquini. No mesmo período, o teatro recebeu commedie di maschere, talvez representadas como intermezzi dos melodramas. ${ }^{42}$ Muito provavelmente tratava-se da mesma companhia que havia se apresentado no Palazzo della Cancelleria, no mesmo período. Neste caso, a companhia de istrioni estaria inserida em um sistema 'coprodutivo', administrado por nobres e empresários que normalmente se ocupavam das representações dos melodramas na maioria dos teatros, públicos e privados, uma espécie de “nobilização" do gênero da commedia dell'arte que entrava no circuito romano mais importante, embora com importância menor em relação ao melodrama. Outro fato que atesta a boa fortuna das commedie di maschere naquele período é a chegada a Roma, em dezembro de 1690, de outras companhias de atores, tanto que, além das apresentações no Teatro della Pace, houve outras também no Teatro Capranica. ${ }^{43}$

A peste iminente e a morte do pontífice Alessandro VIII foram funestas para o carnaval de 1691. Durante um ano foram proibidas comédias com música e as récitas dos atores. ${ }^{44}$ No carnaval de 1692, no entanto, as apresentações de comédias de máscaras foram retomadas na casa Ottoboni, como se infere do aluguel de figurinos de Coviello e de Dottore. ${ }^{45}$

Em março do mesmo ano, o cardeal foi obrigado pelo Papa Innocenzo XII a destruir o teatro de seu palácio. Mas, em 1694, manda construir um novo, ainda

\footnotetext{
${ }^{42}$ Sobre esta notícia que fala da "cadute di Pantalone", ver: Volpicelli, cit., p. 698.

${ }^{43}$ Staffieri, cit. p. 96.

${ }^{44}$ Alberto Cametti. I/ Teatro di Tordinona poi di Apollo, Tivoli, Arti Grafiche Chicca, 1938, II, p. 347, dagli Avvisi nel carteggio mediceo, 13 gen 1691.

45 I-Rvat, vol. 23, n. 35, f. 168v:"A dì d.o [3 febbraio 1692] A quello, che diede due Vestiti, uno da Coviello, et uno da dottore per la Commedia di nolito".
} 
mais impressionante, mas para marionetes. ${ }^{46}$ Ottoboni buscava os textos e a música (arie e villanelle) de apresentações já feitas em teatros romanos. ${ }^{47}$

Seguramente Ottoboni, que havia promovido dois melodramas de Bernardo Pasquini, entre 1690 e 1692, no Seminário Romano, sobre Alessio e Eudossia ${ }^{48}$, conheceu as commedie di maschere com balli e intermezzi com música representadas naquele Seminário no Carnaval de 1693 a 1698 (Tabela IV). Não são conhecidos os autores dos textos destas obras e música, hoje perdidas. As comédias eram apresentadas em forma de scenario ${ }^{49}$, ou em poucas folhas com uma descrição sumária do enredo, do prólogo e dos intermezzi. Como percebemos a partir dos libretos, os atores destas representações eram os próprios seminaristas, coadjuvantes, às vezes, de profissionais.

Tabela IV: Comédia com intervenções musicais no Seminario romano durante o Carnaval

\begin{tabular}{|l|l|l|l|}
\hline 1693 & $\begin{array}{l}\text { Scenario di Plauto alla } \\
\text { moderna }\end{array}$ & $\begin{array}{l}\text { Primeiro intermezzo com música: Pulcinella cacciatore; Segundo } \\
\text { intermezzo com música: Ballo dei paggi. Maestro de ballo: } \\
\text { Fabritio Gatti. } \\
\text { Personagens com máscara: Norcino, Fracassa, Cornacchia, etc. } \\
\text { junto com personagens como Polidoro, Ortenzio, etc. }\end{array}$ & $\begin{array}{l}\text { Rc, } \\
\text { misc. } \\
1731 / 12 .\end{array}$ \\
\hline 1694 & $\begin{array}{l}\text { Scenario del Moro } \\
\text { della bianca fé }\end{array}$ & $\begin{array}{l}\text { intermezzo ballo dei fauni; II int. ballo introdotto in musica da } \\
\text { Appollo e Tersichore }\end{array}$ & $\begin{array}{l}\text { Rc, ms } \\
3788 / 76\end{array}$ \\
\hline 1696 & 'inganno della $_{\text {fantasia }}^{52}$ & $\begin{array}{l}\text { Ao final do I atto: viene introdotto un Musico a cantare in } \\
\text { camera; balli nos intermezzi. } \\
\text { Personagens: Purgone, Scappino, Moscone, etc }\end{array}$ & $\begin{array}{l}\text { Rc, ms. } \\
3788 / 78 .\end{array}$ \\
\hline
\end{tabular}

${ }^{46}$ Sobre a notícia do teatro do palácio da Cancelleria di Ottoboni, cfr. Saverio Franchi, Drammaturgia romana, II (1701-1750), Roma, Edizioni di Storia e Letteratura, 1997, pp. CV-CVIX.

47 I-Rvat, vol. 29, s.n. int, "Denari spesi [...] da me Hippolito Bresciano Per un'Opera presa ha [sic] Capranica della Opera nova che fecero ultima s. :20 Per un opera presa alla pace s_10 per un Opera presa ha Tordinona s_ 10 [tot] _40 lo Hippolito Missidono ho ricevuto li suddetti baiocchi quaranta [feb 1694]"; vol.31: 1) n. 74, f. 242, 3 febbraio 1694, conto di legatura: "villanelle della Pace"; 2) n. 74, conto di legatura., 1695: "villanelle delle Arie della Pace"; 3) n. 5, 1695, f.7v: "ariette della Pace".

${ }^{48}$ Franchi, II, p. CX.

${ }^{49}$ Breve sumário do enredo em prosa não em verso, no libreto da ópera.

${ }^{50}$ Anonimo, Scenario di Plauto alla moderna. Roma: Francesco de' Lazari 1693.

${ }^{51}$ Anonimo, Scenario del Moro della bianca fè. Roma: Francesco de' Lazari 1694.

52 Anonimo. L'inganno della fantasia. Roma: Francesco de' Lazari, 1696. 


\begin{tabular}{|l|l|l|l|}
\hline \hline 1696 & La bugia in gioco $^{53}$ & $\begin{array}{l}\text { Intermezzi com balli. Personagens como Sgannarella, Carcazza, } \\
\text { etc }\end{array}$ & $\begin{array}{l}\text { Rc, ms. } \\
3788 / 79\end{array}$ \\
\hline 1697 & I litiganti ovvero il $_{\text {giudice impazzito }}^{54}$ & $\begin{array}{l}\text { Intermezzi com balli. I int.: L'interesse propone un ballo di } \\
\text { dottori a suon di piastre; II int.: due spiriti ballano }\end{array}$ & $\begin{array}{l}\text { Rc, ms } \\
3788 / 80\end{array}$ \\
\hline 1698 & II vecchio credulo ${ }^{55}$ & $\begin{array}{l}\text { Intermezzi com balli. I int: Ballo di baccanti; II int: ballo di } \\
\text { cinque medici. }\end{array}$ & $\begin{array}{l}\text { Rc, vol. } \\
\text { misc. } \\
1118 / 19\end{array}$ \\
\hline
\end{tabular}

O papa continuava a exercitar sua severidade em relação aos teatros: mandou destruir o Teatro Tordinona por razões de moral pública, em 1697, e proibiu os espetáculos públicos, em 1698. Do mesmo modo, as representações de comédias dos istrioni não tiveram vida fácil.

De modo a contornar as severas imposições do papa, pelo menos a partir de 1697, Ottoboni acolheu o pintor Trevisani, ${ }^{56}$ quem representava comédias no teatro do Pallazzo que Ihe pertencia oficialmente. O teatro foi refeito para o Carnaval de 1698. ${ }^{57}$ Naquela temporada, entre 20 de janeiro e 11 de fevereiro, foram representadas algumas comédias, como percebemos a partir de alguns figurinos alugados: um traje para Cola; uma cimarra (vestido) para dottore, quatro barbas postiças e uma peruca; um capote enfeitado com pele branca de marinheiro; um tamburlucho rosso [...] di Panno guarnito d'Arg.to ${ }^{58}$; uma vestimenta de peregrino (uma túnica e uma de inverno feita de lá) e duas golas grandes. As vestes e acessórios eram alugados de Giovanni Comis mascheraro alla Pace (negociante de máscaras próximo ao Teatro)..$^{59}$ Outras representações de

\footnotetext{
${ }^{53}$ Anonimo, La bugia in gioco. Roma: Francesco de' Lazari, 1696.

${ }^{54}$ Anonimo, I litiganti ovvero il giudice impazzito. Roma: Francesco de' Lazari, 1697.

${ }^{55}$ Anonimo. /l vecchio crédulo. Roma: Stamperia del Lazzari, 1698.

${ }^{56}$ I-Rvat, vol.39, s.n. int., "A dì $47 \mathrm{mbre} 1697$ Lavori [di facchinaggio] fatti per l'Emin.mo Sigr Cardinale Ottoboni [...] e ripresi diversi banchi da Trevisani e riportati al Teatrino, e altre robbe [...] e più riprese dal Sig.re Trevisani per servitio della Commedia sedie e in Guardarobba, e un cimbalino dorato riportato nell'Appartamentino e doi Scabelloni foderati riportati alla Stantia del Giardino".

57 I-Rvat, vol.38, n. 93, f. int 8: il conto dei lavori recava la data del 13 febbraio del 1698.

${ }^{58}$ uma espécie de veste, com pao enfeitado com algo prateado.

59 I-Rvat, vol 39, “Conto dell'Em.o [...] Otthoboni de abbiti dati per le Commedie fatte dall'Sig.ri Trivisani in Cancelleria presi da Gio. Batt.a Cavalletti d'ordine datomi dall'Guardaroba di Sua Em.za Un Abbito da Cola dato alli 20 Gen.ro 1698 et tenuto per tutto l'11 feb.ro detto che fanno gior.te ventidue da cordo à b 19 il giorno s. $3.30 \mathrm{~A}$ dì 24 gen.ro una cimarra da dottore quattro Barbe un Chapello tenuto gior.te quattro $-60 \mathrm{~A}$ dì 28
} 
comédias com máscara foram feitas no Palácio do Cardeal de Albano, vizinho de Roma, onde apresentou-se uma personagem que carregava uma espada ( $i$ recitanti - os intérpretes - tomaram a espada). ${ }^{60}$

O teatro do pintor Trevisani funcionou até o final de 1701, como verificamos nos documentos, mesmo sem notícias quanto às representações a música esteve sempre presente, documentado pelo uso de vários cravos naquele teatro. ${ }^{61}$

A partir de 1700, em Roma, voltaram a surgir várias restrições ainda mais severas: o Papa Clemente XI proibiu os espetáculos durante os dez anos que seguiram as comemorações pelo novo século (1700), pela guerra de sucessão espanhola, e pelo terremoto de 1703. Muitos teatros foram obrigados a fechar suas portas, mesmo que temporariamente, entre eles está o Teatro Pace, reduzido a um grande depósito, e alugado ao Cardeal Ottoboni. ${ }^{62}$

d.o dato un chapotto guarnito di pelle Biancha alla marinara servito sette giorni à dì 19 il giorno -11.5 (?) A dì P.o feb.ro dato un tamburlucho rosso tenuto otto giorno di Panno guarnito d'Arg. [en]to a dì 19 il giorno - 90 (o 80?) E più la cimarra da dottore per otto giorni E più due veste da pelegrino una saia e l'altra di Panno, e dui collari grandi tenuti per dui giorni b. cinq.ta -50 [...]" f.v: "Io infrascritto fede come Giovanni Comis mascheraro alla Pace ho ricevuto [...] scudi sette m.a [...] 9 marzo 1698 [...]". Vol. 39, "Lista di spese fatte [...] nel mese di marzo 1698 da me Pietro Pescatore [...] A dì 8 d.o E per sette b. 65 m.a a Gio. Comis per nolo di diversi vestiti di maschere date nel Carnevale pross. P.to per le commedie fatte dal Trevisani come per conto e ricevuta [...]".

${ }^{60}$ Vol. 39, "Lista di spese fatte [...] nel mese di marzo 1698 da me Pietro Pescatore [...] A dì 8 d.o e d. sette moneta dati a Gasparo Sciape che disse per altrettanti pagati al Capitan Lupelli per prezzo d'una spada, che prestò alli recitanti della commedia, che fece S.E. in Albano, e da essi perduta 7".

${ }^{61}$ No Carnaval de 1699 houve algumas récitas no teatro de Trevisani; por Di Facchini sabemos que alguns cenários e três cravos foram transportados a outros teatros romanos, evidentemente para a repetição do mesmo espetáculo, I-Rvat, vol. 16, s, n. int, 7 marzo 1699: "Lista de' facchini di lavori fatti per la Guardaroba e altro cominciando li 3 febb,o per tutto li 7 marzo 1699 [...] E più per porto e riporto di sciene da Trevisani à Campo Marzio otto viaggi s._60 [...] E più per porto, e riporto, di tre cimboli da Trivisani all'Collegio Nazareno s. 40" Outros transportes de bancos do teatro de Trevisani ao teatro do Cardial foi feito em 1701 I-Rvat, Comp. Ott.:vol.43, s.n."Conto di lavori fatti nel mese di Marzo e noliti di taffetani [...] a dì 4 Gen.ro 1701 [...] Per havere fatto pigliare tutti li Banchi dal S. Trevisano e portarli nel nostro Teatrino b. 30 per porti e riporti di doi cimbali da Chapo le Case all'teatro del Sr Trivisani b. 30".

62 O Cardeal alugou por pelo menos três anos (da settembre 1704 fino almeno a settembre del 1707). Constando como "della Rimessa del Teatro Pace": I-Rvat, vol. 49, n. 61, "Dalli 15 7bre 1704 per tutto xbre 1705 "Francesco Catani muratore lavori in Cancelleria [...] "A dì 30 Xbre 1705 Rimessone che tiene in affitto l'Em.mo e Rev.mo Sig.r Cardinale Ottoboni detto il Teatro della Pace [...]"; vol 50, s.n.int., doc. in data 5 ott. 1705, pagamento da ottobre 1705 a tutto giugno 1706; vol. 52, s.n. int, 28 lug 1706: ricevuta dell'affitto "per pigione di tre mesi a tutto sett.re per rimessa del Teatro Pace, s. 20"; vol. 54, s.n. int, ricevuta "Sig. Marchese Ornani de Cupis sono a conto della Pig.e del Teatrino della Pace 
As crônicas romanas falam genericamente, entre 1699 e 1701, de apresentações de comediantes (istrioni) ${ }^{63}$ ao lado dos palácios dos embaixadores estrangeiros, que não precisavam submeter-se às exigências papais. Muito provavelmente os embaixadores possibilitaram a realização de turnês dos comediantes fora da Itália e a exportação das comédias de máscara para o exterior. Entre o fim do Seiscentos e início do Setecentos, cômicos italianos apresentaram-se na Espanha com a máscara de Truffaldino: os atores tocavam violinos, cantavam arie e dançavam diversas danças, entre elas minuetos, como sabemos pelo tratado de 1716, Nuova e curiosa scuola de' balli teatrali do maestro di ballo veneziano, Gregorio Lambranzi, que havia tomado como modelo os cômicos da Comedie italienne, expulsa de Paris em 1697.64

Fig. 10 - Gregorio Lambranzi, Nuova e curiosa scuola de’ balli teatrali, 1716
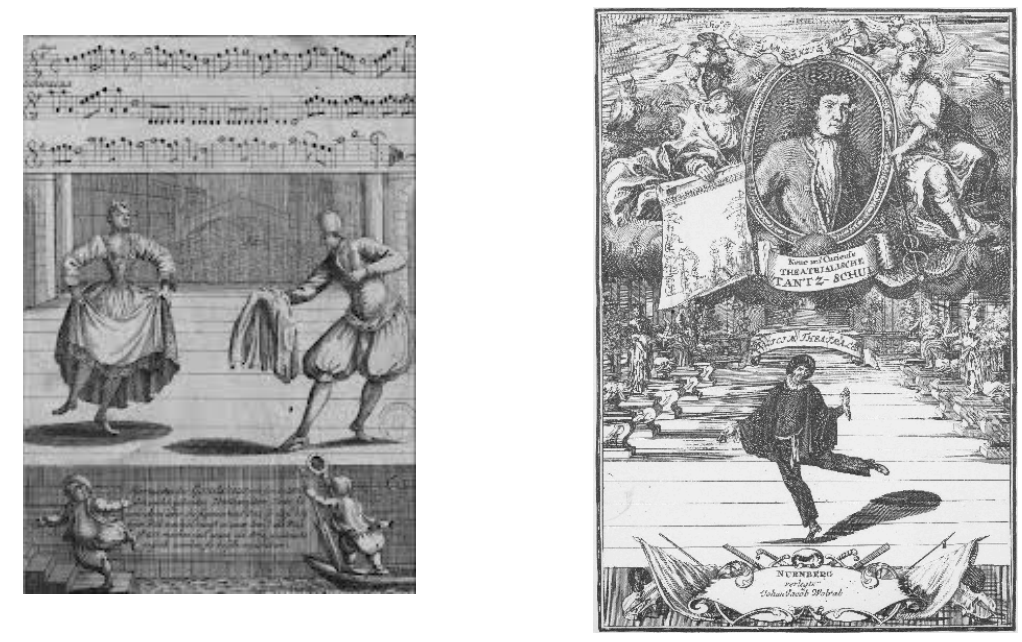

sono 31 luglio [1707] s. 50:30". vol. 52, s.n. int: "Ripartimento [...] luglio 1707 [...] Sig. Marchese Fran.co Flavio Ornani di Cupis per piggione di mesi tre ott.e sett.re prossimo a venire della rimessa del Teatro della Pace [...] 5.20"; Palchetti al Pace per cardinale e la famiglia almeno fino al 1719. Vol. 77, n. 28, 400 scudi.

${ }^{63}$ Giovanni Battista Campello, Pontificato di Innocenzo XII Diario a cura di Paolo Campello Della Spina, Roma, Accademia Storico Giuridica, 1893. Récita de istrioni e burattini p. 133. Em novembro, se denominando genericamente de Teatro Pace, Tor Sanguigna, dos Coronari; p. 134, o carnaval na praça Sciarra e al Babuino.

${ }^{64}$ Gregorio Lambranzi. Nuova e curiosa scuola de' balli teatrali - Neue und curieuse theatrialische Tantz-schul, Nürnberg 1716, 50 incisioni con personaggi della commedia dell'arte. Per Lambranzi, cfr. Silvano Giordano, Lambranzi Gregorio, in Dizionario Biografico degli Italiani, vol. 63, 2004. 
A máscara de Truffaldino passou para a literatura espanhola, graças a uma companhia de cômicos italianos que chegaram em Madrid, em 1703, no séquito de Felipe V. Na comédia El trufaldino espanol y espiritada fingida, de José de Prado, em um dueto entre Eulalia e Colombina, foram citados os compositores Scarlatti e Bononcini. ${ }^{65}$ Mais tarde, no entanto, deu-se a chegada das máscaras italianas em Portugal, ocorrido na metade do século. ${ }^{66}$

Entrementes, em Roma, após o período de restrições dos espetáculos, houve um incremento progressivo das atividades teatrais. Mas, somente em 1719, encontraremos um texto de comédia que apresenta intervenções musicais: // dottore [Balanzone] impaurito, de Carlo Sigismondo Capeci, representado no Teatro de Santa Lucia della Tinta, com cenas puramente musicais, dezesseis arie e coro final. Roma recomeçava a viver de forma mais despreocupada e, enfim, podia entregar-se novamente a uma vida mais leve e divertida.

\section{FONTES}

ANONIMO. Mascherata piacevole "da recitarsi il Carnevale composta nuovamente di un Pulcinella e due Furbi”. Viterbo: Pietro Martinelli, [1675-80].

BOSSI, Melchior. Lo Gnaccara. Orvieto: Rinaldo Ruuli, 1636. A primeira edição da comédia foi feita em Veneza, em 1637.

CAMETTI, Alberto. I/ Teatro di Tordinona poi di Apollo. Tivoli: Arti Grafiche Chicca, 1938, II, p. 347, dagli Avvisi nel carteggio mediceo, 13 gen 1691.

CICOGNINI, Giacinto Andrea. // convitato di pietra. Venezia: Zamboni, 1691.

Contabilidade Ottoboni, Biblioteca Apostólica Vaticana.

CRESCIMBENI, Giovanni Mario. Comentarj [...] intorno alla sua Istoria della Volgar Poesia. Roma: Antonio de' Rossi alla Piazza di Ceri, 1702.

\footnotetext{
${ }^{65}$ Fernando Doménech, Los Trufaldines y el Teatro de los Caños del Peral, Madrid, Editorial Fundamentos, 2007, p. 178; Los libros de cuentas de los corrales de comedias de Madrid: 1706-1719, a cura di John Earl Varey, Charles J. Davis, London, Tamesis books limited, 1992, p. 247-248.

${ }^{66}$ Durante o reinado de Dom José I, a coroa portuguesa recebe uma companhia de teatro que desembarcou em Lisboa, em fins de 1753, início de 1754, proveniente de Genova, que inicia em português a comediografia goldoniana. cfr. Giorgio Padoan, Problemi di critica goldoniana, Volume 16, Centro interuniversitario di studi veneti, Venezia, Longo, 2009, p. 213.
} 
DEL TUFO, Giovanni Battista. Ritratto o modello delle grandezze, delitie e maraviglie della Nob.ma Città di Napoli [...], ms. XIII C 96. Biblioteca Nazionale di Napoli [1588 c.ca].

Descrizzione della barriera e della mascherata fatte in Firenze a XVII e a XI. Firenze: Sermartelli Bartolommeo e F.lli, 1613.

GIOIELLI, Mauro. I balli di Sfessanìa di Jacques Callot, Extra, 29 gennaio 2011 (XVIII), n. 3, p. 17-18.

LAMBRANZI, Gregorio. Nuova e curiosa scuola de' balli teatrali - Neue und curieuse theatrialische Tantz-schul. Nürnberg: 1716.

MERSENNE, Marin. L'Harmonie universelle. Paris: Sébastien Cramoisy, 1636, II, p. 293-294.

MINACCI, Pietro Francesco. // Bernardone. Roma: Michel’Ercole, 1676.

PIANELLI, Giovanni Battista. Li falsi mori. Roma: Grignani, 1638.

SALVIATI, Giovanni Battista. // Tesoro. Roma: Francesco Tizzoni, 1676.

[Tomaso Santagostini], Non v'ha mel senza mosche. Roma: Tizzoni, 1671.

\section{Referências bibliográficas}

ALBERTI, Carmelo. La scena veneziana nell'età di Goldoni. Roma: Bulzoni, 1990.

BALDANO, Giovanni Lorenzo. Libro per scriver l'intavolatura per sonare sopra le sordelline, Savona, ms,1600, Fac-símile do manuscrito e estudo introdutório editado por Maurizio Tarrini, Giovanni Farris, John Henry van der Meer. Savona: Associazione Ligure per la Ricerca delle Fonti Musicali - Editrice Liguria, 1995.

BARBIERI, Patrizio. Musiche e strumenti "alla greca" nel Seicento italiano, in Francesco Buti tra Roma e Parigi: diplomazia, poesia, teatro Atti del Convegno Internazionale di studi, Parma 12-15 dicembre 2007 a cura di Francesco Luisi. Roma: Torre d'Orfeo, 2009.

CAMPEllo, Giovanni Battista. Pontificato di Innocenzo XII Diario a cura di Paolo Campello Della Spina. Roma: Accademia Storico Giuridica, 1893.

CHIRICO, Teresa. L'inedita serenata alla regina Maria Casimira di Polonia: Pietro Ottoboni committente di cantate e serenate (1689-1709), in AAVV. La serenata tra Seicento e Settecento. Musica, poesia, scenotecnica a cura di Nicolò Maccavino, Atti del Convegno Internazionale di Reggio Calabria, 16-17 maggio 2003. Reggio Calabria: Laruffa Editore, 2007, vol. II, p. 397-449.

. Strumenti a corde e a fiato e strumentisti in casa Ottoboni all'epoca di Händel a Roma in $A A V V$., Georg Friedrich Händel in Rom. Beiträge Internationalen Tagung am Deutschen Historischen Institut in Rom a cura di Sabine Ehrmann-Herfort e Matthias Schnettger, Atti del Convegno Internazionale 
di Roma, 17-20 ottobre 2007, Analecta musicologica, vol 44 (2010). Kassel: Bärenreiter-Verlag, p. 291-306.

. Noticias inéditas sobre instrumentos de teclado, constructores y musicos en Roma, en la corte del principe cardenal Pietro Ottoboni entre los anos 1689 y 1719. in AAVV, Domenico Scarlatti en España a cura di Luisa Morales, Atti del Convegno Internazionale di Garrucha, 2006-2007, Garrucha, Leal, 2009, p. 143-159.

- Harpsichords and Harpsichords makers employed in Rome by Cardinal Pietro Ottoboni and his Father Antonio, The Galpin Society Journal, vol. LXII (2009), p. 101-115.

. La vicenda di Adonìa nelle opere di Girolamo Frigimelica Roberti (1695) e Pietro Ottoboni (1699). Un unico progetto ottoboniano?, in AAVV., Musikstadt Rom. Geschichte Forschung Perspektiven. Beiträge der Tagung "Rom, Atti del Convegno internazionale a cura di Markus Engelhardt, Roma, 28-30 settembre 2004 Analecta musicologica, vol. 45 (2011). Kassel: Bärenreiter, p. 218-262.

DER MEER, John Henry van. Strumenti musicali europei del Museo Civico Medievale di Bologna. Bologna: Nuova Alfa Editoriale, 1993.

Dizionario Biografico degli Italiani, vol. 63, 2004.

DOMÉNECH, Fernando. Los Trufaldines y el Teatro de los Caños del Peral, Madrid, Editorial Fundamentos, 2007, p. 178; Los libros de cuentas de los corrales de comedias de Madrid: 1706-1719, a cura di John Earl Varey, Charles J. Davis. London: Tamesis books limited, 1992, p. 247-248.

FERRERO, Mercedes Viale. Antonio e Pietro Ottoboni e alcuni melodrammi da loro ideati o promossi a Roma in Venezia e il melodramma nel Settecento a c. di Maria Teresa Muraro. Firenze: Olschki 1978.

FRANCHI, Saverio. Drammaturgia romana: Repertorio bibliografico cronologico dei testi drammatici pubblicati a Roma e nel Lazio, Secolo XVII. Roma: Edizioni di Storia e Letteratura, 1988.

. Drammaturgia romana, II (1701-1750). Roma: Edizioni di Storia e Letteratura, 1997, p. CV-CVIX.

LA VIA, Stefano. II cardinale Ottoboni e la musica: nuovi documenti (1700-1740), nuove lettere ed ipotesi in Intorno a Locatelli. Studi in occasione del tricentenario della nascita di Pietro Antonio Locatelli (1695-1764) a cura di Albert Dunning, Lucca: LIM, 1995, I, p. 319-526.

MARX, Hans Joachim. Die Musik am Hofe Pietro Kardinal Ottoboni unter Arcangelo Corelli, Analecta musicologica, V (1968), p. 104-177.

MEGALE, Teresa. Gabrielli Francesco detto Scapino o Scappino, in Dizionario Biografico degli Italiani, vol. 51, 1998.

MICHEL, Olivie., Bricci (Briccio, Brissio, Brizio), Giovanni, Dizionario Biografico degli Italiani, vol. 14 (1972). 
MICHELASSI, Nicola. La Finta pazza a Firenze: commedie 'spagnole' e 'veneziane' nel teatro di Baldracca (1641 - 1665), Studi secenteschi, 2000, pp. 317-325.

O’NEILL, Barry, The Sordellina. a Possible Origin of the Irish Regulators, The Seán Reid Society Journal, Vol. 2, November 2001.

PADOAN, Giorgio. Problemi di critica goldoniana, Vol. 16, Centro interuniversitario di studi veneti. Venezia: Longo, 2009.

PANDOLFI, Vito. Siro Ferrone, La Commedia dell'arte: storia e testo, Vol. 5, 1988.

RASI, Luigi. I comici italiani, biografia, bibliografia, iconografia, L-Z, II,1905, p. 693-694.

STAFFIERI, Gloria. Colligite fragmenta. La vita musicale romana negli Avvisi Marescotti (1683-1707). Lucca: LIM, 1990, p. 94-95.

WALKER, Thomas. Dalla "Finta pazza" alla "Veremonda": storie di Febiarmonici, Rivista italiana di musicologia, X 1975, p. 223-227.

VOLPICELLI, Maria Letizia. I/ Teatro del Cardinale Ottoboni al Palazzo della Cancelleria in II teatro a Roma nel Settecento, a cura del Servizio Attività Culturali dell'Istituto dell'Enciclopedia Italiana. Roma: Istituto della Enciclopedia Italiana, 1989 (Biblioteca internazionale di cultura, 21), II, p. 681-782. 